\title{
Development and evaluation of an enzyme-linked immunoassay for the prostate: specific antigen utilizing two monoclonal antibodies
}

\author{
D. Zundel ${ }^{1}$, H. Jarry ${ }^{1}$, D. Kestler ${ }^{1}$, G. Holzapfel ${ }^{1}$, H. Bartels ${ }^{2}$, K. H. Scheit ${ }^{3}$, and W. Wuttke ${ }^{1}$ \\ 1 Division of Clinical and Experimental Endocrinology, University of Göttingen, Göttingen \\ ${ }^{2}$ Department of Urology, Hospital "Weende", Göttingen, and \\ ${ }^{3}$ Max-Planck-Institute for Biophysical Chemistry, Göttingen, FRG
}

Accepted: November 1, 1989

\begin{abstract}
Summary. PSA is an important tumor-marker for prostatic cancer disease. We developed a sensitive, simple and inexpensive Sandwich ELISA for PSA with two monoclonal antibodies. The precision and reliability of the assay are reflected in the low inter- and intraassay coefficient of variation. PSA was not detectable in sera from normal females $(n=50)$. Sera from males with different serum levels of PSA (normal males, patients with prostate hypertrophy, prostate cancer patients, $n=79$ ) and 15 prostate cancer patients treated with Zoladex were measured by our ELISA and by a commercially available RIA. The correlation coefficient between these both testsystems was close to $1(r=0.97)$.
\end{abstract}

Kew words: Prostate-specific antigen - ELISA - Clinical validation

Measurement of serum concentrations of tumor-associated antigens is a suitable and specific method for therapeutic monitoring of the disease in prostatic cancer patients. Two antigens are of major importance, namely, prostate acid phosphatase (PAP) and prostate-specific antigen. There is ample evidence that both tumor markers are suitable for evaluating the clinical stage of prostate cancer development $[9,12,13]$. However, several clinical studies have revealed that PSA is superior to PAP since PSA serum levels are more closely related to the clinical stage of the disease and treatment response than PAP levels $[5,10]$.

Another methodological advantage of PSA determinations in comparison to measurement of PAP in serum samples is the greater stabibility of the PSA molecule in the blood than that of PAP. Thus specific treatment of the serum samples to prevent degradation of PSA is not required, which increases the practicability of PSA determination compared to PAP measurements.

The majority of commercially available PSA assays is based on radioimmunological methods. A sandwich ELISA available for PSA (Hybritech, Hürth-Efferen, FRG) requires specific laboratory equipment like a specially designed photometer. The aim of the present study was therefore to develop a sensitive but inexpensive Sandwich ELISA based on microtiter plates (MTP) that can be performed in each diagnostic laboratory with standard equipment.

\section{Materials and methods}

\section{PSA purification}

PSA was purified from seminal plasma obtained from healthy men. Proteins were precipitated with increasing concentrations of ammonium sulphate (AS). The highest yield of PSA was obtained with a $70 \%$ final concentration of AS. The protein precipitate was redissolved in water and dialyzed against $50 \mathrm{mmol}$ TRIS buffer, pH 7.4. The material was then chromatographed on Superose S12 (Pharmacia, Freiburg, FRG) and fractions were analyzed for PSA content by a commercially available PSA RIA (Biermann, Bad Nauheim, FRG). The protein composition of the obtained fractions was analyzed by SDS PAGE electrophoresis. Highly purified native PSA, donated by Prof. K.H. Scheit, served as the reference preparation.

\section{Fusion protocol}

The fractions with the highest PSA content were concentrated by ultrafiltration (Amicon, Witten, FRG, PM 10 membrane). This PSA-containing fraction, which was devoid of any serum albumin, was used to immunize female balb/c-mice. Four-week-old female mice were inoculated i.p. with partially purified PSA emulsified in complete Freund's adjuvans (PSA content per injection $40 \mu \mathrm{g}$, as determined by RIA). Injections ( $40 \mu \mathrm{g}$ PSA in incomplete Freund's adjuvans) were repeated every 2 weeks for 3 months. To stimulate spleenocytes PSA ( $40 \mu \mathrm{g}$ dissolved in phosphate-buffered saline = PBS) was injected daily 3 days prior to fusion, which was performed according to the protocol described by Köhler and Milstein [6]. Hybridoma cells were dispersed into 480 wells (Nunc, Kamstrup, Denmark; 24 well plates) and fed with HAT medium. On day 10 post-fusion supernatants were screened for binding to PSA in a solid-phase ELISA using $50 \mathrm{ng} / \mathrm{ml}$ highly purified PSA as plate coat. The PSA antibody complex was visualized with a peroxidase-labeled 


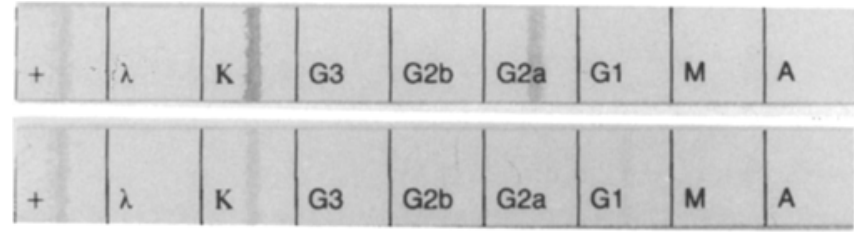

Fig. 1. Determination of IgG subclasses of mAK 43G11 and 4D7. MAK 43G11 (upper line) belongs to subclass $\operatorname{IgG}_{2 a}, \mathrm{mAK} 4 \mathrm{D} 7 \mathrm{is}$ an antibody of the IgG1 subclass

anti-mouse IgG antibody obtained from DAKO (Hamburg, FRG). Enzyme reaction was carried out as described below. In addition, the ability of the supernatants to bind a radioactive PSA tracer was tested. As a third test system for positive fusion supernatants, Western blotting $[1,11]$ of the AS fraction of seminal plasma was employed. Only those supernatants of hybridoma cells that gave a specific and sufficient reading in all three test systems were considered for subcloning. From 480 wells 62 positive clones were obtained. Upon subcloning, 2 clones named 4D7 and 43G11 were selected for mass production of monoclonal antibodies (mAK). Addition index of clones was determined using a solid-phase ELISA and data were calculated according to the formula given by Friquet et al. [4].

\section{Mass production of $m A K s$}

Clones were grown in a serum-free medium based on DMEM (Gibco, Karlsruhe FRG), supplemented with $0.2 \%$ PSA, $100 \mathrm{IU} / \mathrm{ml}$ penicillin, $100 \mu \mathrm{g} / \mathrm{ml}$ streptomycin and $10 \mathrm{ml} / 1$ nutridoma SP (Boehringer, Mannheim FRG). Collected cell culture medium was concentrated by ultrafiltration and proteins were precipitated with AS. Immunoglobulins were purified by protein A chromatography (Pharmacia, Freiburg FRG) [3]. The specificity of the selected clones was documented by Western blotting of the complex protein mixture of AS fraction of seminal plasma. IgG subclasses were determined using an antibody isotype kit (Amersham, Braunschweig FRG).

\section{Sandwich ELISA}

The monoclonal antibody $43 \mathrm{G} 11$ served as base of the immunocomplex. Every second well of a 96-well MTP (Nunc, Kamstrup, Denmark) was coated with $50 \mu \mathrm{l}$ of a $20 \mu \mathrm{g} / \mathrm{ml}$ solution of $\mathrm{mAK}$ 43G11. The wells not coated with $\mathrm{mAK}$ were used to determine the blank reading of each individual blood sample. Incubation was carried out at $4{ }^{\circ} \mathrm{C}$ overnight. All of the following ELISA steps were performed at room temperature. $0.5 \%$ BSA solution $(200 \mathrm{ml})$ was added to each well to block the remaining binding sites. Plates were thoroughly washed three times with $0.05 \%$ Tween 20 in PS. Samples $(40 \mu \mathrm{g} /$ well $)$ were incubated for $1.5 \mathrm{~h}$. After three washing steps with PBS/Tween, the second mAK 4D7 was labeled with horse radish peroxidase according to the method of Nakane and Kawaoi [8] and added to each well. Incubation was continued another $30 \mathrm{~min}$. After the final washing steps (three times PBS/Tween) the substrate solution (tetramethylbenzidine, Sigma, Deisenhofen, FRG) was added to each well at a volume of $150 \mu l$ and enzyme reaction was carried out for $30 \mathrm{~min}$. Reaction was stopped by the addition of $50 \mu \mathrm{l}$ of $2.5 \mathrm{~mol} \mathrm{H}_{2} \mathrm{SO}_{4}$ and quantified using a standard ELISA photometer at a wavelength of $450 \mathrm{~nm}$.

\section{Serum samples}

To compare a commercially available RIA (Biermann, Bad Nauheim, FRG) with the ELISA following serum samples were analyzed:

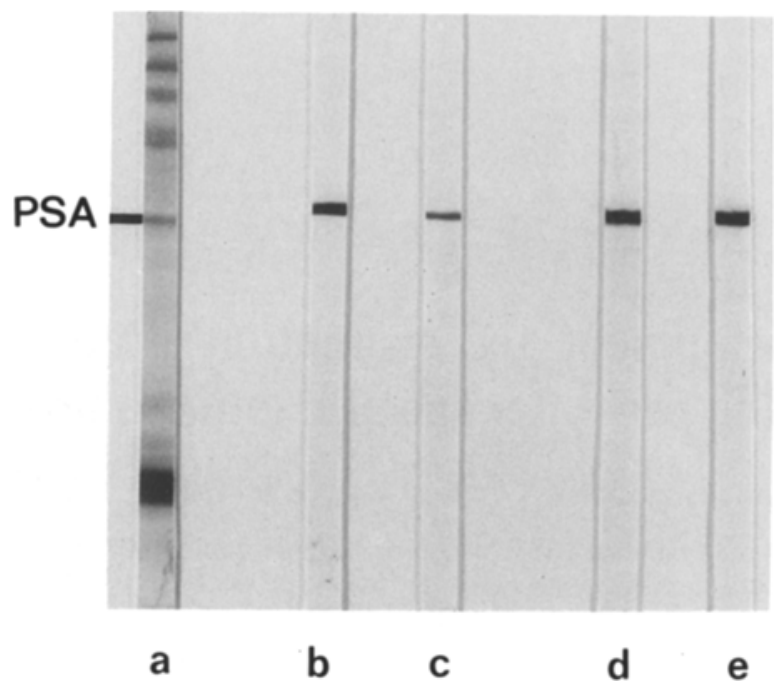

Fig. 2. Western blot analysis of 43G11 $(b=1: 500, c=1: 5000)$ and 4D7 $(d=1: 5000, e=1: 50,000)$

a. Sera from urological patients (79 samples) with known PSA values (as previously determined by RIA) covering a range from $1 \mathrm{ng} / \mathrm{ml}$ (normal males) up to more than $100 \mathrm{ng} / \mathrm{ml}$ (prostate cancer patients).

b. Sera from healthy females $(n=50)$.

c. Sera from prostate cancer patients treated with Zoladex. In these sera, the time course of PSA levels in response to therapy was determined (15 patients).

\section{Results}

Of 480 hybridoma cell supernatants, 62 contained antibodies reactive with PSA in the solid-phase ELISA. These positive supernatants were also examined with the Western blot and RIA test. We obtained 22 positive and specific supernatants of fusion products that were subjected to subcloning. Upon subcloning, we finally obtained two monoclonal antibodies (43G11 and 4D7) that recognized two different epitopes of the PSA molecule, as determined by the positive addition index of $80.5 \%$. Classification of IgGs subtypes revealed that mAK 4D7 is an antibody of the IgG 1 subclass whereas $\mathrm{mAK} 43 \mathrm{G} 11$ is an IgG of the subclass 2-alpha (Fig. 1). Both antibodies are highly specific for PSA (Fig. 2), as in Western blots of ammonium-sulfate-precipitated proteins of the seminal plasma, only one, namely the PSA band, was recognized by both mAKs.

Cross-reactivities of the monoclonal antibodies employed for the Sandwich ELISA were tested against prolactin, HCG, AFP, CEA, CA19-9, Ferritin and PAP. These compounds were used in concentrations up to $100-$ fold of the norm values.

The intra- and interassay variance on the basis of measurements in sera with normal and pathologically increased PSA concentrations is given in Table 1. Precision within an assay never exceeded $6 \%$ and was at $15 \%$ between assays at very low concentrations. 
Table 1. Variances

\begin{tabular}{lccc}
\hline Intra-assay variance & & & \\
\hline Serum sample & 1 & 2 & 3 \\
\hline Number of replicates & 12 & 12 & 12 \\
Mean (ng/ml) & 5.6 & 7.6 & 24.4 \\
Standard deviation & 0.3 & 0.5 & 1.1 \\
Coefficient of variation & 5.3 & 6.0 & 4.4 \\
\hline
\end{tabular}

Inter-assay variance

\begin{tabular}{lccc}
\hline Serum sample & 4 & 5 & 6 \\
\hline Number of assay & \multicolumn{1}{c}{5} & 6 & 6 \\
Mean (ng/ml) & 3.0 & 12.1 & 46.3 \\
Standard deviation & 0.5 & 0.5 & 1.7 \\
Coefficient of variaton & 15.8 & 4.3 & 4.7 \\
\hline
\end{tabular}

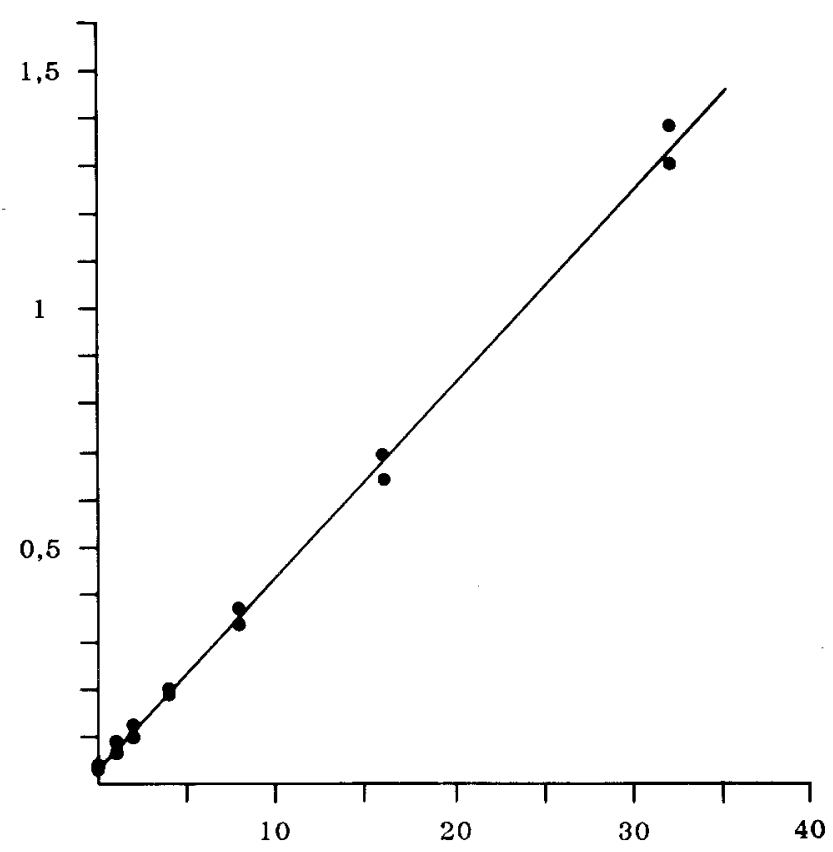

Fig. 3. Representative standard curve of the sandwich ELISA

A representative standard curve of the sandwich ELISA is shown in Fig. 3. The sensitivity of the assay, as defined as the mean absorbence value of the zero standard plus three times standard deviation, was below $2 \mathrm{ng} / \mathrm{ml}$. Highly purified PSA dissolved in female serum was used as standard. Female serum without addition of PSA was used as the zero standard. The working range of the developed ELISA is $2-60 \mathrm{ng} / \mathrm{ml}$.

The reproducibility of our ELISA is demonstrated in Fig. 4. This figure depicts the superposition of five standard curves as measured at 5-day intervals with the same lot of reagents. It is apparent that all five standard curves are similar regarding sensitivity and the working range of the assay. The high reproducibility of the assay is reflected

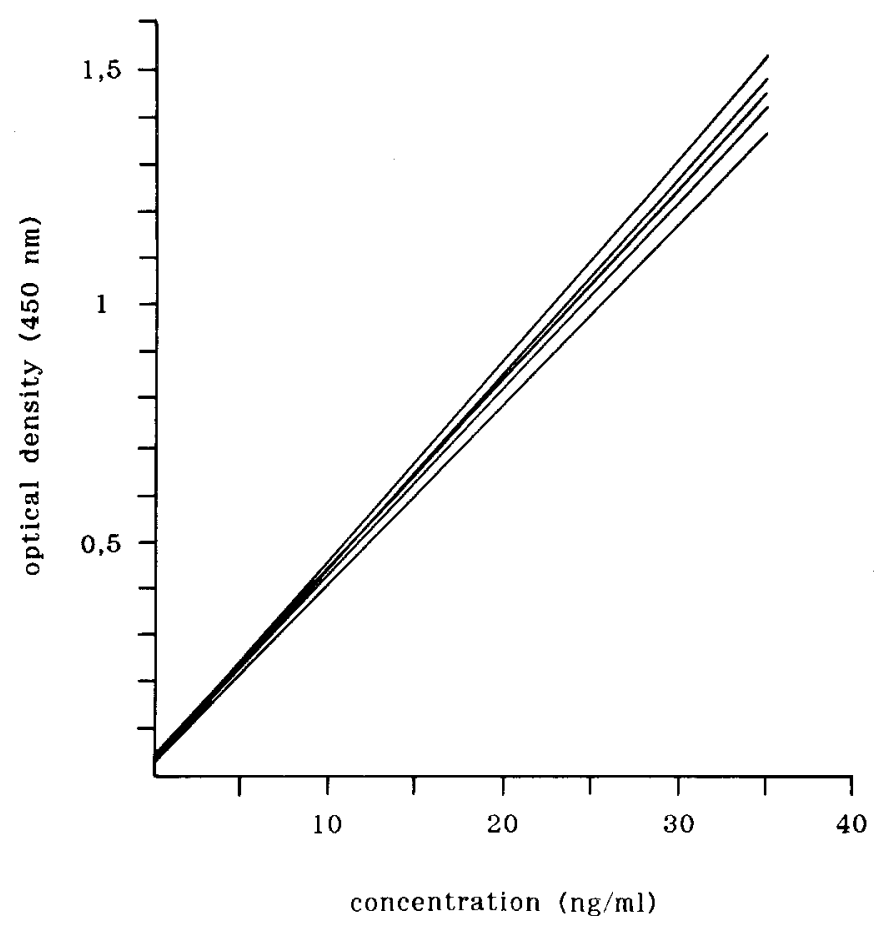

Fig. 4. Five standard curves of the sandwich ELISA measured at 5day intervals

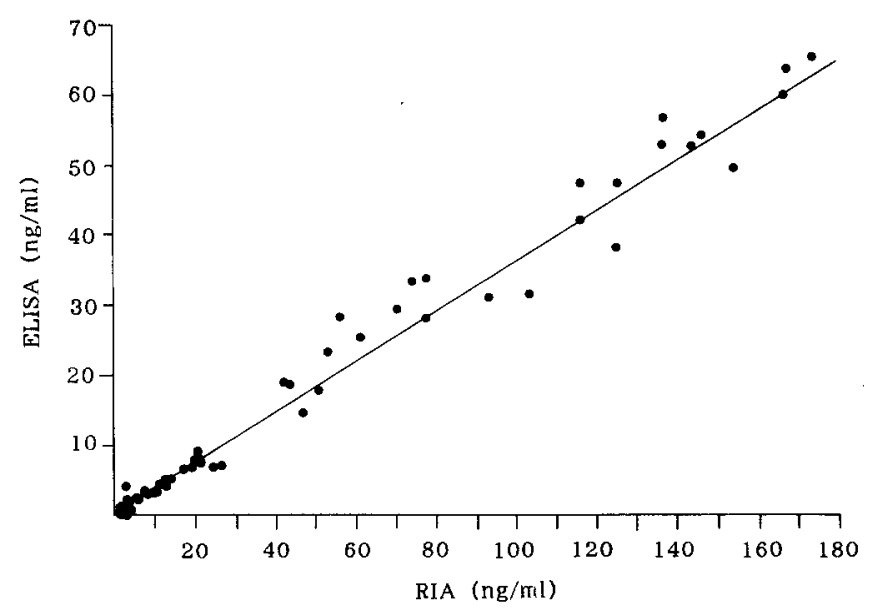

Fig. 5. Correlation between the sandwich ELISA and a commercially available PSA-RIA $(n=79)$

by the intra- and interassay variances summarized in Table 1.

In order to demonstrate the validity of our ELISA sera from urological patients with different PSA values $(n=79)$, the PSA levels were measured in a commercially available PSA RIA (Biermann, Bad Nauheim, FRG) and in our ELISA (Fig. 5). It is evident that both test systems are highly correlate. The correlation coefficient is close to $1(r=0.97)$. None of the sera from healthy women yielded a positive reading (data not shown).

The time course of PSA levels in three prostate cancer patients treated with Zoladex, a potent GnRH agonist, in order to inhibit testosterone secretion are shown in Fig. 6. These patients showed different responses to therapy. 


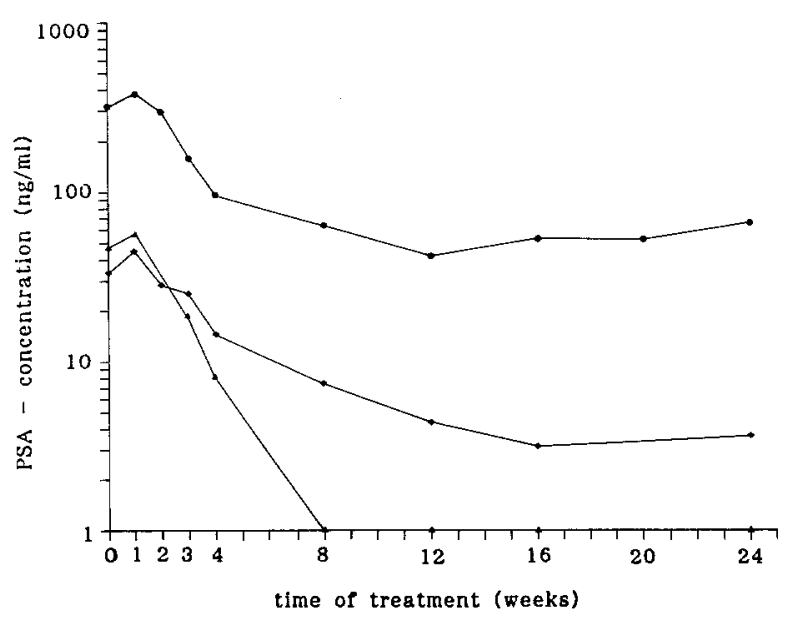

Fig. 6. Time course of PSA levels (measured with the sandwich ELISA) in three prostate cancer patients who have been treated with Zoladex and have shown different responses to this therapy

Declining PSA levels represent successful therapy (lower curve).

\section{Discussion}

We report the development and validation of a sensitive sandwich ELISA, which proved to be a reliable tool for determining serum PSA levels. In comparison to commercially available PSA test systems, our Sandwich ELISA has several advantages: (a) since it is a non-isotopic assay the radioactive reagents must not be handled and no contaminated waste is produced; (b) the assay procedure is very rapid (if precoated plates were used, the total assay time was only $2.5 \mathrm{~h}$; (c) the assay does not require special photometers or other special laboratory equipment.

The sensitivity of the ELISA is below $2 \mathrm{ng} / \mathrm{ml}$. Actually, the borderline concentrations between physiological and pathological PSA concentrations are about $4 \mathrm{ng} / \mathrm{ml}$ [7]. In the range below $5 \mathrm{ng} / \mathrm{ml}$ the intra-assay variance of our ELISA is about $5 \%$, which points to a high precision of the determinations. Since PSA determinations are used to recognize growth and the progression of metastasis, our assay is sensitive enough to detect minute amounts of PSA in the blood of patients - even when PSA levels are in the normal range.

The validity of our ELISA is documented by the excellent correlation of ELISA values with RIA values. The correlation coefficient is 0.97 and is highly significant. There is no non-specific interference of serum compounds with the reagents of the ELISA since all sera examined from the women yielded readings similiar to the blank.

We employed our ELISA to follow of the PSA concentrations in patients with prostate cancer undergoing treatment with Zoladex. This GnRH agonist inhibits pituitary LH secretion, which results in reduced testicular testosterone release. Many prostate cancers are androgen dependent; thus, reduction of endogenous androgen production is a suitable therapy to prevent tumor progression. Declining testosterone values are accompanied by declining PSA levels, which is detectable with both the commercially available RIA and the ELISA developed.
Thus, the lower curve in Fig. 6 represents successful therapy.

Altough the correlation between PSA values determined in the RIA and ELISA is excellent, the absolute values measured in the ELISA are always lower than those measured in the RIA. Similar results have been reported by Chan et al. [2]. These authors compared a polyclonal versus a monoclonal test system and also consistently found lower PSA values when measured by the monoclonal IRMA than with the polyclonal PSA-RIA.

In summary, we have developed a sensitive, rapid, and inexpensive ELISA, which allows determination of PSA levels in the sera of prostate carcinoma patients. The assay can be performed in each laboratory equipped with standard laboratory equipment. The complete assay only requires less than $3 \mathrm{~h}$ if a batch of precoated plates has been prepared previously.

\section{References}

1. Bernette WN (1981) "Western blotting": electrophoretic transfer of proteins from sodium-dodecyl-sulfate polyacrylamide gels to unmodified nitrocellulose and radiographic detection with antibody and radioiodonated protein A. Anal Biochem 112:195

2. Chan DW, Bruzek DJ, Oestering JE, Rock RC, Walsh PC (1987) Prostate-specific as a marker for prostatic cancer: a monoclonal and a polyclonal immunoassay compared. Clin Chem 33:1916

3. Forsgren A, Sjoquist (1966) Protein A from S. aurens. I. Pseudoimmune reaction with human gamma-globulin. J Immunol 97:822

4. Friquet B, Djavadi-Ohaniance L, Pages J, Bussard A, Goldberg M (1983) A convenient enzyme-linked immunosorbent assay for testing whether monoclonal anftibodies recognized the same antigenic site. Application to hybridomas specific for the $\beta 2$ subunit of Escherichia coli tryphtophan synthase. J Immunol Meth 60:351

5. Killian CS, Lawrence JE, Vargas FP, Yang N, Wand MC, Priori RL, Murphy GP, Chu TM (1986) Relative reliability of five serially measured markers for prognosis of progression in prostate cancer. J Natl Cancer Inst 76:179

6. Köhler G, Milstein C (1975) Continuous cultures of fused cells secreting antibody of predifined specifity. Nature 256:495

7. Kuriyama M, Wang MC, Papsidero LD, Killian CS, Shimano T, Valenzuela L, Nishiura G, Murphy GP, Chu TM (1980) Quantitation of prostate-specific antigen in serum by a sensitive enzyme immunoassay. Cancer Res 40:4568

8. Nakane PK, Kawaoi A (1974) Peroxidase-labeled antibody. A new method of conjugation. J Histochem Cytochem 22:1084

9. Romas NA (1987) Tumor markers for prostate cancer: update. World J Urol 5:85

10. Stamey TA, Yang N, Hay AL, McNeal JE, Freiha FS, Redwine E (1987) Prostate-specific antigen as a serum marker for adenocarcinoma of the prostate. N Engl J Med 317:909

11. Taubin H, Staehelin T, Gordan J (1979) Electrophoretic transfer of proteins from polyacrylamid gels to nitro cellulose sheets: procedure and some applications. Proc Nat1 Acad Sci USA 76:4350

12. Wang MC, Papsidero LD, Kuriyama M, Valenzuela LA, Murphy GP, Chu TM (1981) Prostate antigen - a new potential marker for prostate cancer. Prostate 2:89

13. Yam LT (1974) Clinical significance of the human acid phosphatase. Am J Med 56:606

Dr. Henning Bartels

Abteilung für Urologie

Evangelisches Krankenhaus Weende

An der Lutter 24

W-3400 Göttingen

Federal Republic of Germany 